\title{
FEMININITY IN VIDEO GAMES: AN ANALYSIS OF GENDER IN TERMS OF VISUAL ASPECTS, NARRATIVE AND SOCIABILITY
}

\author{
Mariana Michels Fontoura and Marília A. Amaral \\ Federal University of Technology - Paraná(UTFPR), Postgraduate Program in Technology and Society, \\ Curitiba, Brazil
}

\begin{abstract}
The role of gender in the design of technologies has been a topic of growing importance in fields such as Interaction Design, HCI and Games. Understanding that technology development and use practices emerge within the cultural processes, we analyze notions of traditional femininity in technology, as well as new approaches to female representation. The issues discussed and briefly analyzed in this essay point to a production and regulation of gender by technologies such as video games. Our goal in this paper, therefore, is to assess how gender impacts design and the use of digital games in terms of visuals, narrative and sociability.
\end{abstract}

\section{KEYWORDS}

Gender, Femininity, Representation, Games

\section{INTRODUCTION}

This paper starts with the premise that technology development and use practices emerge within social and cultural processes. That means that technology's historical heritage and the developers' context influence its processes and products (Bardzell, 2010). Video games, as technological artifacts, are equally affected by the social, historical and cultural dynamics. The role of gender in designing technologies has been a topic of growing importance in fields such as Interaction design and HCI (Bardzell, 2010; Breslin and Wadhwa, 2014), and Games (Shaw, 2014; Cassel and Jenkins, 2000; Rodrigues, 2014; Goulart and Nardi, 2017). In this paper, our goal is to analyze the influence of gender norms in the development and use of video games. This paper starts with a theorical discussion of essential terms to ground our brief analysis. First, we analyze three characters from the game "Overwatch". Later, we analyze a few players' shared experiences that concerns gender and game discussions. Our analysis takes into consideration: visual aspects, narrative and sociability. The visual and narrative factors are considered relevant because they take part in the development and design of games. The sociability factor is relevant because it focuses on how players act upon gender in video games. Without further ado, we intent to discuss how gender norms, identities and relations shape the design of video games, as well as the ways the notion of femininity can be reinforced or subverted by its use.

\section{GENDER}

In this paper, gender is approached by denying the ideas that men and women are essentially and naturally different. We understand that this vision would reinforce stereotypes, and would rely on opposing characteristics. Our approach draws on the notion introduced by Simone de Beauvoir, that "one is not born a woman, but rather, becomes a woman" (De Beauvoir, 1989), which provides a distinction between sex (biological sexual identity assigned to one when they were born) and gender (behaviors, values, and other attributes associated to femininity and masculinity). Breslin and Wadhwa (2014[b]) point out that this implies that being female and being a woman do not mean the same thing, and also these categories are not necessarily associated. With this approach to gender as socially constructed, we intent to deviate from universal notions of 
"men" and "women" and understand that people are able to belong or not to these categories. Still, it is important to acknowledge that in many cultures around the world there are societal norms and habits that associate femininity and being female (Breslin and Wadhwa, 2014[b]).

Besides the notion of gender, in order to theoretically ground the discussion, there is another relevant concept to our analysis. Inspired in the work of Michel Foucault, De Lauretis (1987, pp.38) developed the concept of "technology of gender", that means "the techniques and discursive strategies by which gender is constructed [...]". Rodrigues (2017) provides us the understanding that these techniques and discourses are embed in video games. Based on De Lauretis' concept, Rodrigues (2017) suggests that gender relations are constructed by these gender technologies, therefore creating and reaffirming subject positions. The work of Wajcman (2004, pp.7) presents the notion of technology as a sociotechnical product, that is, "shaped in social relations that use and produce it". Wajcman explains the mutually shaping relationship between gender and technology, comprehending that technology is not only a consequence, but also a source of gender relations.

Based on these concepts, like Rodrigues (2017), we propose to analyze games as technologies of gender that reaffirm notions of femininity and masculinity and produce gender identities. We also highlight the role of institutionalized discourses in the construction of gender, once they have reached the digital space within technologies such as video games.

\subsection{Technology}

Technology development and use practices emerge within social and cultural processes. That statement leads to the conclusion that values and societal norms may influence the design of technologies. In the HCI field, the works of Breslin and Wadhwa (2014) emphasize the role of gender in the design and use of technologies. The problematics of ignoring gender in the design of technologies are that the artifacts being developed will implicitly embed scripts about play and usage behavior based on the developer's experiences. Since the majority of developers, in the United States and Europe for instance, are white, middle class males, it often leads to hindrances on women's use (Breslin and Wadhwa, 2014[b]). On the other hand, focusing on gender differences, the project tends to reinforce stereotypes tied to ideas of essential and natural differences between women and men (Breslin and Wadhwa, 2014[a]).

Originated from the "girls' game' movement", the pink games are an example of designing technology for women. Often it reaffirms stereotypes tied to the feminine culture, such as fashion, beauty care and motherhood (Rodrigues and Merkle, 2017). According to Rodrigues and Merkle (2017), based on Warren's (2015) work, the separation of games by gender originates from the toys marketing logic. The authors point out that this reiterates not only gender stereotypes, but also expectations based on notions of femininity and masculinity. While "girl games" represent stereotyped notions of femininity, relating women to passive and permissive roles, the categorization of "boy games" present themselves problematic as well, maintaining themes culturally comprehended as masculine, such as competitiveness, war, violence and roles related to domination, tied to boys (Rodrigues and Merkle, 2017). The hierarchy between games understood as belonging to male culture or female culture becomes clear.

The argument used to justify the development of pink games is the notion that it represents girls' tastes, and for that reason are consequently profitable (Rodrigues 2017). Such excuse not only shows the traditional notion of femininity incorporated in the digital realm, but also reinforces values and expectations over the female players. That doesn't mean that women won't or shouldn't play and enjoy these games. What we argue is that their use of technology should not be limited by gender roles, neither by notions of traditional femininity. There should be space for multiple femininities.

Technology is often portrayed as part of a masculine culture. As Wajcman (2004, pp.15) points out, "schooling, youth cultures, the family and the mass media all transmit meanings and values that identify masculinity with machines and technological competence". She describes that as the sex-stereotyping of technology, and argues that it portrays the field as appropriate to men, creating a hindrance for women that want to "enter" technology fields. To enter that world, women must forsake their femininity, in order to belong. We argue that this happens not only in technological work fields, but also with technological products, such as video games. Also, this traces a territory where men and women can enact their masculinity or femininity, as well as when they are able to do that freely. Just like women have to forsake their femininity to enter technological fields, men are also tied to gender norms that require them to forsake their masculinity to enter in fields associated to feminine culture, such as fashion design for instance. 


\subsection{Femininities}

Gender varies cross-culturally, and for that reason there is not a universal model of femininity or masculinity. Notions of what is "natural" or not are constructed in the cultural processes, which means that the notion of natural "gender" identities are also being constructed in the cultural dynamics (Louro, 2000). The cultural context influences the gender identities, notions of femininity/masculinity, and behaviors that are enacted.

According to Louro (2000) the sexology of the 19th century defined what was considered normal/natural masculinity and femininity as distinct characteristics of men and women (as a biological classification ${ }^{1}$ ). This produced a hierarchy between gender identities, since some values and behaviors are considered appropriate to a specific gender, and not to the other. This distinction also produced notions of normal and abnormal subjects towards gender identities, based on how the person is (or is not) conforming to gender norms. While some values and roles are expected of men, others are expected of women, delimiting how a subject can enact his/her gender. Also, the oppositional binary categories are relevant to understand how the hierarchy of power is grounded, since one is defined by its relation to the norm (Rodrigues, 2014). Femininity is constructed as the opposition to masculinity, so masculinity is taken as the norm, and femininity is a deviation from that same norm.

\section{FEMININITY IN VIDEO GAMES}

Gender values and norms are tied to notions of femininity and masculinity. The ways this is translated into visual language, narrative aspects of stories and sociability between players are approached in this section. Also, this section is divided into three parts. The first is about the visual aspects of gender representation in video games, focusing on character design. According to Flick (2009) visual content such as films and photos are not only data but instruments of knowledge. A case study described in Flick's (2009) book points to the use of visual material, as complementary documentation to the textual form, on analyzing culture and practices.

Also, we believe that video games contain social reflections and experiences, which are relevant to this paper. The second part is dedicated to the narrative content regarding femininity and gender norms, highlighting plot stereotypes associated to female representation and to the femininity in general. In the third and last part of this section we assess a few gaming informal documentation practices in a brief analysis on how gender roles and relations influences communication among players. The analysis presented in section 3.2.2 and 3.3 rely on the theoretical basis that are grounding this paper.

\subsection{Visual Aspects}

The visual aspects of femininity are often portrayed as stereotypical elements; the color pink, ribbons, make-up and high heels, for instance. Rodrigues (2014) explains that character design can be a device to reinforce gender stereotypes, pointing out that not only the female representation, but the femininity itself is sexually objectified. These representations are related to societal values and expectations over gender and sexuality. The work of Romanus (2012) discusses the representations of femininities and masculinities in video games. According to Romanus (2012), just like in advertising, the creation and design of characters in video games presupposes a male spectator. Romanus (2012), points out that the way femininities are understood in the popular culture is influenced by the invention and popularization of the computer and the internet, originating images of "digital" women and men. In her essay, Romanus (2012), analyses graphic representations of characters in video games, such as Metroid, Tomb Raider and Devil May Cry. The importance of these analyses is that stereotypes are taken as a place for resistance and questioning of these cultural representations. For that, it must be considered the available social and cultural representations for subjects to identify with, always remembering that these are embedded with values and societal norms.

Video games have shown, throughout the years, a wide range of visual styles for characters, from the abstract designs to the most realistic aesthetics. Hamm (2010) points out that male characters present a large range of body types and facial features, while female characters present a lack of diversity. Even though women are represented in many games, these representations are not diverse. She points out that the game "Team

\footnotetext{
${ }^{1}$ The original terminology in portuguese is "homens e mulheres biológicos".
} 
Fortress 2", by Valve Corporation, is a good example of variety of character designs. These characters silhouettes can be seen in the figure 1 , and are all male. The design of these characters is diverse, and creative. What Hamm intends by showing their silhouettes is to criticize the homogeny in the design of female characters, suggesting that they can be as diverse as the characters represented in Team Fortress 2.

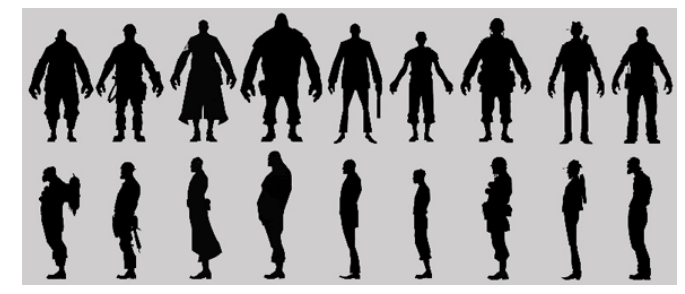

Figure 1. Team Fortress 2 characters silhouettes ${ }^{2}$

The lack of diversity in representing female bodies tends to show only one way of being woman, and that's usually hypersexualized and conforming to the societal standards of female beauty (young, thin...). The hyper-sexualization of female characters is tied to the presumption that gamers are heterosexual males, and for that reason the design is targeted at them. This also works as a mechanism to avoid the homoerotic gaze of male characters, by only sexualizing the female characters (Rodrigues and Merkle, 2017). The many ways of being a man or being a woman are always socially suggested, announced, promoted (Louro, 2000), besides being regulated, condemned and denied. The recurrent eroticized representation of the female characters regulates both genders by constantly representing the imagery of a specific type of desirable woman (large breasts, thin waist, submissive, hero's prize to be won...), as well as the player's expected sexuality (who is supposed to be interested in these representations).

Rodrigues and Merkle (2017) discuss in their essay about the customization tools for characters in video games. The tools are seen as technologies of gender, offering in a scale of masculinities and femininities the ways one can be a man or a woman, producing notions of viable subjects/bodies. According to Rodrigues and Merkle (2017) gender notions are constructed based on the biological sex, and the parameters for customizations of physical attributes and clothing are tied to it, having particular anatomic features.

\subsection{Narrative}

Femininity is explored in the visual content of games, as it has been argued in the previous section, but the ways in which it is explored in the narrative content tends to be less evident. While visual content is more explicit on representation, narrative content is presented through various means, such as values and ideas on the game's plot. The presence of stereotypes appears not only in the graphic part of the games, but can also be present in the characters' plots, the game's universe and other types of narrative content. This topic is about this regard, focusing on the character's plot.

\subsubsection{Damsel in Distress}

The role of the damsel in distress can be seen in several prominent franchises, such as Mario, The Legend of Zelda, Dragon Quest, amongst others. Anita Sarkeesian (2013) in her web series "Tropes vs Women" presents several aspects of female disempowerment stemming from this stereotype. According to Sarkeesian (2013), "as a trope the damsel in distress is a plot device in which a female character is placed in a perilous situation from which she cannot escape on her own and must be rescued by a male character, usually providing a core incentive or motivation for the protagonist's quest"3. Sarkeesian (2013) analyses the damsel through the subject/object dichotomy, understanding that while subjects act, the objects are acted upon. In the damsel trope, the protagonists are the subjects, and this role is associated to men, while the damsels are the objects, often associated to women. The later most often is reduced to "a prize to be won, a treasure to be found or a goal to be achieved" (Sarkeesian, 2013).

\footnotetext{
${ }^{2} \operatorname{Hamm}(2010)$

3 Transcription of 3'10' to 3'39' from the episode 1, Tropes vs Women: Damsel in Distress. Available in: https://feministfrequency.com/video/damsel-in-distress-part-1/
} 
The damsel role traces expectations and regulations about femininity and gender roles. The mechanism of the damsel trope reaffirms a culture of submission and dependency of the feminine over the masculine (Rodrigues, 2014), representing the feminine culture as lacking of agency. Rodrigues (2014) points out that this stereotype also works as a device to produce ideas of feminine fragility and inexperience, reinforcing a devaluation of femininity. Arantes (2016) discusses the universalization of gender categories (man and woman), pointing out that gender institutes a hierarchical role, which reinforces inequality amongst the notions of femininity and masculinity. Once gender notions reach the "digital realm", they influence not only the technological production, but the very participation in this fields is tied to the hierarchical gender relations

Although the trope of the Damsel in Distress is more evident in women's representations, this trope can also be observed in games that present other types of female characters, such as anthropomorphic animals (as in Starfox Adventures and Sonic CD).

\subsubsection{Character's Plot}

Productions involving female characters are commonly criticized because of the undeveloped backgrounds and plots, which maintain the representation of them as young, attractive, sidekick or the hero's prize. Hamm's (2010) analysis of the game "Gears of War" point to the very same problem. While the male characters are huge and represented with "battle-scarred forms", Lieutenant Anya Stroud, the only female character in the game, seems to be a lot younger than the male characters, besides having a flawless appearance. According to Hamm (2010) "her personality is calm, her background is undeveloped and she seems very detached from the game, as if she were included only to represent a pretty face".

Even though Hamm's analysis was written in 2010, it remains a fairly current topic. Lima (2018), for instance, discusses gender representation in crowdfounded games. His analysis starts with the hypothesis that independent game producers that rely on crowdfunding have the potential to be more diverse on gender representations than the big names of game industry. At the end of his analysis, the conclusion pointed to the opposite direction. According to Lima (2018), even though independent developers that rely on crowdfounding campaigns have more creative freedom, new constrains arise for them by the backers as they participate on the creation process. Therefore, not only the AAA games, but also independent productions are still below expectations on female representation (Lima, 2018).

Despite this little diverse scenario, there has been some changes. A few games have been moving towards subverting these femininity stereotypes and the lack of female protagonism, featuring stories and plots as well developed as the male characters' have been for years. Blizzard Entertainment's first-person shooter game, Overwatch, is a strong example of that. The game explores multiple platforms to construct its stories and backgrounds, even outside the game itself. Extra content can be accessed through their official website, containing comics, informative pages of each character and cinematic videos. Overwatch stands out because of the diversity represented amongst the female characters, in both visual and narrative aspects, deviating from the traditional notions of femininity. We selected three characters to exemplify this, and also for a briefly analysis.
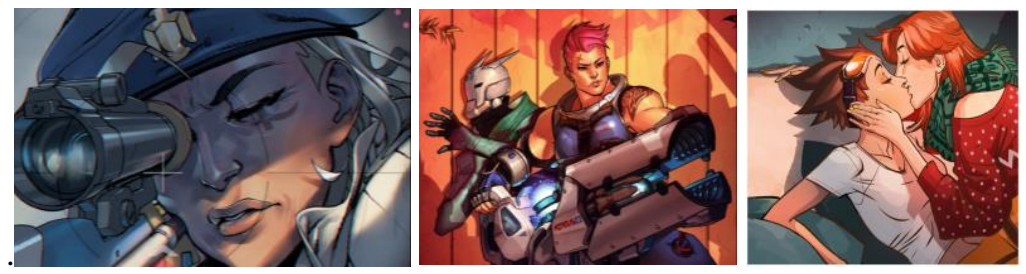

Figure 2. Overwatch characters: Ana, Zarya and Tracer ${ }^{4}$

Ana Amari, on the left side of figure 2, is one of the founding members of Overwatch ${ }^{5}$. She is an Egyptian ex-commander and snipper, considered to be the world's best. What stands out in Ana's story is her age and high ranking in the hierarchy at Overwatch organization. She remained active until the age of 50, when she got seriously injured in battle, even losing her right eye. Ana represents an elderly woman (now at her sixties) that

\footnotetext{
${ }^{4}$ All images were taken from Overwatch original comics. From left to right, their titles are: Legacy, Searching and Reflections. These are available at: https://playoverwatch.com/en-us/media/

${ }^{5}$ Available at: https://playoverwatch.com/en-us/heroes/ana/
} 
has severe war injuries and scars, elements that contrasts the notion of flawless beauty commonly depicted in female characters, and the age limit for female characters to remain active in stories.

Aleksandra Zaryanova, also known as Zarya, is represented in the middle of figure 2. According to the official website of Overwatch, she is "one of the world's strongest women, a celebrated athlete who sacrificed personal glory to protect her family, friends, and country in a time of war" ${ }^{26}$. Zarya is a 28 -year-old Russian soldier whose goal is to help her people recover from post-war destruction, related to the conflicts that have taken place in the game's universe. The first deviation from the traditional femininity lies in the identification of the character with bodybuilding, in addition to a war-oriented narrative. Her story also influences the character's design, resulting in battle-scarred muscles and scars.

The third character is Tracer, whose full name is Lena Oxton. This character stresses differently the notions of gender and sexuality. First of all, she is a core character, appearing on both the cover of the physical edition of the game and the banner for digital purchase. Since Tracer is one of the most popular characters, it caused great controversy when the Christmas comic "Reflections" came out in December of 2016, and Tracer is shown kissing her girlfriend. Some players responses to that were quite problematic, such as posted in the Blizzard's online forum by the player "IgorJCorrea": "in fact the problem is to meet her as a normal/regular girl, and after almost a year 'out of nowhere' a lesbian kiss scene shows up" . By that reaction, and others presented by players in the official forum, when sexuality is not explicitly shown, the character is considered heterosexual. That is to say, when no sexuality is represented, the character is associated to the normative sexuality. According to this perspective, normal/regular girls are heterosexual, and Tracer, when not conforming to gender/sexuality norms, is pointed as abnormal. That leads us to think that the traditional notion of femininity does not include lesbian women. Therefore, gender regulation itself will also take into account other factors such as sexuality.

\subsection{Sociability}

As videogames become more and more popular, it is important to understand the ways in which communication and socialization between players have a meaning to the gaming experience. In the 1990s and 2000s, game magazines were very popular ways of sharing passwords, tutorials and even tips on how to surpass challenging parts of a game. At the time, this was not only a popular way to access game content, but also players experiences. Later, another common practice arose from the gaming community, as players started to share content in websites, allowing other players to comment and respond. It is interesting to note that people consume games in different ways, and looking at forms of documentation reveals diverse appropriations of these technologies, as well as unexpected uses. Speedruns are a kind of appropriation practice, that consist in beating a game in the least time possible. There are a lot of categories of speedruns, such as completing the game with a $100 \%$ "save" (that is, accomplishing everything that is expected in the game, for instance: collecting all the coins, beating all the bosses...), or even by using glitches to beat the game. Summoning Salt is a Youtuber who documents iconic speedruns on vintage consoles, such as Super Nintendo, and Nintendo64. In one of his videos ${ }^{8}$, he explains how the documentation of time records were (and are) done. It started with players contacting each other via email, later becoming more accessible to others by posts in websites, till the uploading or streaming of videos, which is now a popular and more trusting way of sharing time records. Summoning Salt's documentaries are a strong example of how the gaming community can appropriate different ways of playing and even organize itself to document their achievements.

New technologies are being developed, and the exchange of information between players has been facilitated. There are many ways that one can socialize and communicate with other players in the gaming community, such as voice chats, forums, video recording and even streaming live for an audience. Some experiences involving this interaction among players will be highlighted in this topic. The first is a video ${ }^{9}$ shared by Glisa, an Overwatch player. Glisa recorded 16 minutes of harassments during a competitive match of the game. By the beginning of the match, Glisa started to be harassed without even contacting her team

\footnotetext{
${ }^{6}$ Available at: https://playoverwatch.com/en-us/heroes/zarya/

${ }^{7}$ In the original language: "na real o problema é você conhecer ela como uma menina normal e depois de quase um ano "do nada" aparecer uma cena de beijo lésbico...'. Available at: https://us.battle.net/forums/pt/overwatch/topic/20752537624

8 Summoning Salt. Choco Mountain: The History of Mario Kart 64's Most Infamous Track. Available at: https://www.youtube.com/watch?v=Y99Wj-NStok\&ab_channel=SummoningSalt

${ }^{9}$ Available at: https://youtu.be/9f4dW1YpuoA
} 
mates though the voice chat. That means the only representation of femininity associated to her was the character she chose, called Mercy. The provocations directed at Glisa at first concerned her character, like the phrases "I like how Mercy is trying to heal me because she wants me", or about her beauty, as in "Mercy, cure me. I will not call you ugly again. Just kidding, you're probably ugly"10. After Glisa contacted her team on the voice chat, the offenses changed from a figurative aggression to the feminine (that is, the female character), and became directed to the player. The offenses documented by Glisa had contents such as: condemning her for being a woman and playing the game, blaming her for the team's failure and associating her with domestic housework spaces (such as laundry room and kitchen). What draws our attention to this video is how the harassment started in the character, and not in the female player, meaning that in order to experience such harassments one can be symbolically associated with femininity, but doesn't require to be a female.

The second example takes place in the in the role-play servers of World of Warcraft, game developed also by Blizzard Entertainment. The tavern known as the "Goldshire Inn" has become a meeting point for players who enjoy erotic role-play, i.e. performing characters for erotic purposes. A problem pointed in the interview conducted by Motherboard with players (Schott, 2017), is the rape fantasies that some players are performing. The role-play is performed through the character's actions and the messages sent by the chat system of the game, which means that, similar to the case described in the previous paragraph, violence is associated with a female figure without necessarily an identification of the player with it. It is important to highlight that even though there is no need to be a woman to experience these harassments, when experienced by one it is very meaningful, since women already experience this type of violence outside the online environment.

This final paragraph approaches the production of online content by people who subvert patterns of femininity and masculinity. The first example is the Brazilian drag queen Samira Close ${ }^{11}$, who streams games like Fortnite, Life is Strange and League of Legends. The character is performed by a homosexual man named Wenner Pereira, having a strong relationship with the LGBTQ community and related subjects. Samira is highlighted in this section for playing a female role through drag, in the online game environment. That is, in an environment understood as masculine. Other subversive streamers also considered relevant are: Anaxisde ${ }^{12}$, woman who has sought to work as an eSports commentator; and Mandy Candy ${ }^{13}$, transgender woman who is a game streamer. What is interesting is how these diverse manifestations of gender have gained space in the context of games through tools for transmitting and publishing videos.

\section{CONCLUSION}

The issues discussed throughout this essay point to a production and regulation of gender by technologies such as video games. It is important to understand that the cultural and social context, outside the digital environment, influence the production of games, taking into these fanciful universes various gender regulations. It is also emphasized that the consumption and appropriations made by players is quite relevant to understand how femininities and masculinities can be incorporated into the project by the developers, but also can be subverted in the use, and vice versa.

Also, assuming the audience as masculine and heterosexual shapes production, not only in the implicit narratives, but in the design itself. There are many ways to escape from the scope of traditional femininity and present it in a more multiple and diverse way. Allowing characters to be more open to what is understood as feminine and masculine can aid in the process of not producing only one possible form of male / female subject. Promoting positive values linked to femininity can also challenge this hierarchical relation that makes femininity little explored and valued in video games. It is suggested at the end of this essay that if it is possible to think of fanciful universes in games, with mystical creatures, superpowers... it is also possible to detach itself from the traditional stereotypes of femininity and masculinity, and to be creative in the ways of representing these universes.

\footnotetext{
${ }^{10}$ Transcript dialogues from 0'21" to 0'38".

${ }^{11}$ More information available at Samira Close's YouTube Channel: https://www.youtube.com/channel/UCnkhaZ34q4Dw9pgrpBkTcHg

12 More information available at Anaxisde's YouTube channel: https://www.youtube.com/channel/UCfOpQkN8hNfvNLxqCNRzwhQ?a b_channel=AnaXisde

${ }^{13}$ More information available at Mandy Candy's YouTube channel: https://www.youtube.com/channel/UC0UMjthdcI-0IqgaZaQ5_Ww
} 


\section{ACKNOWLEDGEMENT}

This paper is only viable because of the work of Letícia Rodrigues. Her work is responsible for putting Teresa de Lauretis' perspective in game analysis and discussions in Brazil, which provided us with the possibility to analyze games as technologies of gender. We owe her a special thanks.

\section{REFERENCES}

Arantes, M. L. P., 2016. Sexismo nos Campos de Justiça: O Posicionamento de Marca Interferindo na Jogabilidade de League of Legends. Universidade Federal do Paraná, Curitiba, Brazil.

Bardzell, S., 2010. Feminist HCI: Taking Stock and Outlining an Agenda for Design. Proceedings of the SIGCHI Conference on Human Factors in Computing Systems. Atlanta, USA, pp. 1301-1310.

Breslin, S. and Wadhwa, B., 2014. EnGendering Interaction Design. Proceedings of the 3rd International Conference on User Science and Engineering (i-USEr). Shah Alam, Malaysia, pp. 292-295.

Breslin, S and Wadhwa, B., 2014. Exploring Nuanced Gender Perspectives Within the HCI Community. Proceedings of the India HCI 2014 Conference on Human Computer Interaction, New Delhi, India, pp. 45-54.

Cassell, J. and Jenkins, H., 2000. From Barbie to Mortal Kombat: gender and computer games. The MIT Press, Cambridge, USA.

De Beauvoir, S., 1989. The Second Sex. Vintage, New York, USA.

De Lauretis, T., 1987. Technologies of Gender: Essays on Theory, Film, and Fiction. Indiana University Press, Bloomington and Indianopolis, USA.

Flick, U., 2009. Introdução à pesquisa qualitativa. Artmed, Porto Alegre, Brazil.

Goulart, L. and Nardi, H., 2017, GAMERGATE: digital games culture and male gamer identity. In Revista Mídia e Cotidiano: artigo seção livre, Vol. 11. No. 3, pp 250 -268.

Hamm, S., 2010. The Aesthetics of Unique Video Game Characters. Available at: http://gamecareerguide.com/features/854/the_aesthetics_of_unique_video_.php?page=1. Last access: 17/09/2018.

Lima, L. A. B., 2018. The struggles of diversity in gaming: an analysis of gender representation in crowdfunded games. Proceedings of SBGames 2018. Foz do Iguaçu, Brazil, pp. $902-907$.

Louro, G. L., 2000. O corpo educado: pedagogias da sexualidade. Editora Autêntica. Belo Horizonte, Brazil.

Rodrigues, L., 2014. Um Estudo em Representações Gráficas nos Jogos Eletrônicos na Perspectiva de Gênero: Os Tipos de Feminilidade em League of Legends. Universidade Tecnológica Federal do Paraná, Curitiba, Brazil.

Rodrigues, L., 2017. Questões de Gênero em Jogos Digitais: uma coleção de recursos educacionais abertos de apoio à mobilização. Universidade Tecnológica Federal do Paraná, Curitiba, Brazil.

Rodrigues, L. and Merkle, L. E., 2017. Tecnologias de gênero na customização de personagens em jogos digitais. Seminário Internacional Fazendo Gênero 11 \& 13th Women's Worlds Congress. Florianópolis, Brazil. pp. 1-13.

Romanus, J. S., 2012. Gênero em Jogo: Um olhar sobre personagens e as representações de tipos de feminilidades e masculinidades nos games de ação contemporâneos. Universidade Tecnológica Federal do Paraná. Curitiba, Brazil.

Sarkeesian, A., 2013 Feminist Frequency. Tropes vs Women: Damsel in Distress 1. Available at: http://www.feministfrequency.com/2013/03/damsel-in-distress-part-1/. Last Access: 13/09/2018.

Schott, D., 2017. 'World of Warcraft' Has a Rape Problem. Motherboard. Available at https://motherboard.vice.com/en_us/article/mb7b9q/world-of-warcraft-has-a-rape-problem?utm_source=mbtwitter. Last Access: 24/10/2018.

Shaw, A., 2014, Gaming at the edge: sexuality and gender at the margins of gamer culture. University of Minnesota Press, Minneapolis, USA.

Wajcman, J., 2004. TechnoFeminism. Polity Press, Cambridge, England.

Warren, J., 2015. 'Why Do "Girl Games" Matter?'. Game/Show, PBS Digital Studios. Available at: https://www.youtube.comwatch?v=4GKZ-u0cJsI 